Arch. Vet. Scienc., 4(1):57-59, 1999

Printed in Brazil

\title{
TESTE COM LINHAGENS COMERCIAIS DE FRANGO DE CORTE - AVALIAÇÃO DOS PARÂMETROS ZOOTÉCNICOS
}

\author{
JOSÉ SIDNEY FLEMMING ${ }^{1}$; STEPHAN A. JANZEN ${ }^{2}$; MÁRCIA AKENI ENDO ${ }^{2}$ \\ ${ }^{1}$ Professor Titular, Departamento de Zootecnia do Setor de Ciências Agrárias da UFPR, \\ ${ }^{2}$ Acadêmicos do Curso de Medicina Veterinária da UFPR, Bolsistas do Programa Institucional de Bolsas de \\ Iniciação Científica - PIBIC - CNPq.
}

\begin{abstract}
An experiment has been carried out to evaluate performance of the different commercial broiler lineages used in Brazil. The following lineages were tested: Ross, Cobb, Hubbard, Arbor Acres and Isa Vedette in order to evaluate the parameters: average daily gain, feed consumption, feed conversion. A total of 3200 birds were used in this test, distributed in five treatments with four repetitions per treatment, in a experimental design completely randomized. The results were compared by a Random Tukey test. The broilers were fed a corn, soymeal diet conventional used in the integration and slaughtered at 47 days of age. The Ross lineage showed a trend for a better performance, since this lineage, although yielding the lowest live weight, showed the lowest feed consumption, with the best feed conversion. However, these results have not proved statistically significant $(\mathrm{P}>0.05)$.
\end{abstract}

RESUMO - Realizou-se um experimento para avaliar o desempenho zootécnico de diferentes linhagens comerciais de frangos de corte de uso comum no Brasil. Foram testadas as linhagens: Ross, Cobb, Hubbard, Arbor Acres e Isa Vedete avaliando-se os seguintes parâmetros zootécnicos: ganho de peso, consumo de ração e conversão alimentar. Foram utilizadas no teste um total de 3200 aves, distribuídas em cinco tratamentos com quatro repetições por tratamento, num Delineamento Completamente Casualizado, sendo os resultados comparados por um teste de médias. As aves foram alimentadas com ração à base de milho e soja, de uso convencional na integração, e abatidas aos 47 dias de idade. A linhagem Ross apresentou melhor conversão alimentar; com peso vivo relativamente baixo, contudo, esses resultados não se mostraram estatisticamente significativos $(\mathrm{P}>0,05)$.

\section{Introdução}

A avicultura atual tem grande importância na produção de proteíina animal a baixo custo, apresentando uma evolução contínua com o desenvolvimento de inúmeras pesquisas cujo objetivo é promover o melhoramento genético das diferentes linhagens comercias de frangos de corte (GIANNONI e GIANNONI, 1983; PEREIRA, 1983). Essa constante melhora no material genético faz com que a formulação e a elaboração das rações seja continuadamente corrigida acompanhando o nível nutricional exigido pelas linhagens. (ANDRIGUETTO et al., 1996).

Objetivando o melhor desempenho, as diferentes linhagens de frangos comerciais sofrem consecutivas seleções e o produto material terá maior valor sempre que apresentar melhores condições de adaptação às diferentes regiões do País com diferentes modelos de criação, assim como um aumento de resistência às mais diversas patologias que afetam o plantel avícola.

Este projeto foi desenvolvido com a finalidade de testar e selecionar, para determinada região, uma ou mais linhagens de frango de corte que apresentem boa adaptação, com excelente conversão alimentar e apreciável ganho de peso.

A linhagem Ross apresenta-se como uma linhagem de excelentes resultados no Brasil com ótima conversão alimentar resultando em uma carcaça com bom rendimento muscular, principalmente de pernas e peito (PERFORMANCE OBJECTIVES, 1995; ROSS BREEDERS, 1995; ROSS BROILER, 1996).

A linhagem Cobb-500 é enfatizada segundo a empresa produtora (COBB BROILER, 1992; COBB VANTRESS, 1994) como sendo uma ave de ótima conversão alimentar, bom peso médio, excelentes cortes de peito e com moderado desenvolvimento de pernas.

A linhagem comercial Hubbard apresenta bom ganho de peso e conversão alimentar com satisfatório rendimento de carcaça, valorizando o desenvolvimento de pernas (HUBBARD FARMS, 1992; 1995; 1996).

A linhagem Arbor Acres, no seu manual técnico ARBOR ACRES FARM (1996) caracteriza-se pela maior rusticidade com menor sensibilidade às doenças, apresentando bom ganho de peso e conversão alimentar.

A linhagem Isa Vedette caracteriza-se como reprodutora, sendo as fêmeas de pequeno porte e os machos bem desenvolvidos. O cruzamento destas aves leva a um vigor híbrido, com o produto tendendo a um maior peso, esperando-se uma ave de bom desenvolvimento corporal e baixo consumo de ração (ISA VEDETTE, 1996).

$\mathrm{O}$ projeto teve como objetivo avaliar alguns 
parâmetros zootécnicos das cinco linhagens comerciais dos frangos de corte a saber: Ross, Cobb, Hubbard, Arbor Acres e Isa Vedette. Foram mensurados: conversão alimentar, consumo de ração e ganho de peso para cada linhagem.

O conhecimento e a divulgação destes resultados permitem ao avicultor escolher corretamente a linhagem que melhor se adapta à sua região, considerando-se o desempenho, o manejo e a sanidade das aves com sua relação custo-benefício.

\section{Material e Métodos}

O experimento foi realizado na COPACOL (Cooperativa Agrícola Consolata Ltda.), na cidade de Cafelândia, PR. Utilizou-se um aviário com 20 celas, com capacidade para 160 aves por cela. As condições de manejo e equipamentos são aquelas de uso convencional na região. Foram testadas as linhagens comerciais disponíveis no mercado nacional: Ross, Cobb, Hubbard, Arbor Acres e Isa Vedette.

Foram efetuados cinco tratamentos, com quatro repetições.
T-1 ( Cross )
T-4 (Arbor Acres)
$\mathrm{T}-2$ ( Coob )
T-5 ( Isa Vedette )
T-3 ( Hubbard )

Foi utilizado um Delineamento Completamente Casualizado (D.C.C.) e as médias avaliadas por um teste de médias (Teste de Tukey).

\section{Resultados e Discussão}

Ganho de peso (peso vivo). Não houve diferença significativa $(\mathrm{P}>0.10)$ entre os tratamentos. Os dados de média de ganho de peso são apresentados na Tabela 1 em ordem decrescente:

Tabela 1. Ganho de peso do início aos 47 dias de idade.

\begin{tabular}{l|c|c}
\hline \multicolumn{1}{c|}{ Tratamentos (linhagens) } & Peso médio $(\mathrm{g})$ & Diferença entre o melhor e os demais $(\mathrm{g})$ \\
\hline T-3 ( Hubbard ) & 2260.0 & - \\
T-4 (Arbor Acres ) & 2251.0 & 09.0 \\
T-1 ( Ross ) & 2236.0 & 24,0 \\
T-2 ( Cobb ) & 2235.0 & 25.0 \\
T-5 ( Isa ) & 2184.0 & 76.0 \\
\hline
\end{tabular}

A diferença entre os tratamentos ( DMS ) para ser significativa $(\mathrm{P}<0.10)$ deveria ser no mínimo de 95,.0 gramas.

Apesar da tendência da linhagem Hubbard apresentar um melhor peso, este número não é significativo ( $\mathrm{P}>0.10$ ) havendo, assim $90 \%$ de probabilidade desse resultado não se repetir.
Consumo de ração. Os dados de consumo de ração, avaliados no teste, são mostrados na Tabela 2 estando ordenados do maior para o menor valor de consumo:

Tabela 2. Consumo de ração do início aos 47 dias de idade.

\begin{tabular}{l|c|c}
\hline \multicolumn{1}{c|}{ Tratamentos (linhagens) } & Peso médio $(\mathrm{g})$ & Diferença entre o maior e os demais $(\mathrm{g})$ \\
\hline T-4 ( Arbor Acres) & 4365.0 & - \\
T-3 ( Hubbard ) & 4352.0 & 13.0 \\
T-1 ( Ross ) & 4266.0 & 99.0 \\
T-5 ( Isa ) & 4264.0 & 101.0 \\
T-2 ( Cobb ) & 4259.0 & 106.0 \\
\hline
\end{tabular}

A linhagem Cobb é aquela que consome menor quantidade de ração $(\mathrm{P}<0.10)$. As demais linhagens não diferem estatisticamente entre si, com uma tendência das linhagens Ross e Isa a se aproximarem ao consumo da Cobb. As linhagens Arbor Acres e Hubbard são aquelas que apresentaram uma tendência a consumir maior quantidade de ração.

Conversão Alimentar. Os dados de conversão alimentar ao se comparar as diferentes linhagens não foram significativos $(\mathrm{P}>0.10)$. Os valores estão listados na Tabela 3 da melhor para a pior conversão:

Tabela 3. Conversão alimentar do início aos 47 dias de idade.

\begin{tabular}{l|c|c}
\multicolumn{1}{c|}{ Tratamentos (linhagens) } & Conversão Alimentar & Diferença entre o melhor e os demais \\
\hline T-2 (Cobb) & 1,906 & - \\
T-1 (Ross) & 1,909 & 3.0 \\
T-3 (Hubbard) & 1,925 & 19.0 \\
T-4 (Arbor Acres) & 1,932 & 32.0 \\
T-5 (Isa) & 1,952 & 46.0 \\
\hline
\end{tabular}

A diferença entre os tratamentos (DMS) para ser considerada significativa $(\mathrm{P}<0.10)$ deveria ser de 75.0 gramas de ração/kg de ave produzida. 
Existe uma tendência da linhagem Cobb ser a melhor em termos de conversão alimentar, contudo conclui-se com $90 \%$ de certeza, que na realização de um novo teste, este resultado se repetiria.

Assim com respeito ao parâmetro ganho de peso, não se observou diferença no desempenho das linhagens . $(\mathrm{P}>0.10)$. Na observação dos dados que dizem respeito ao consumo de ração, verifica-se uma tendência das linhagens Arbor Acres e Hubbard em consumirem uma maior quantidade de ração, contudo a avaliação estatística dos resultados demonstra serem diferenças não significativas $(\mathrm{P}>0.05)$. A linhagem Ross apresenta uma tendência a bons resultados em relação à conversão alimentar e ao consumo de ração, apesar de não significativos.

Avaliando-se os resultados da conversão alimentar, observa-se uma tendência das linhagens Cobb e Ross a converterem maior quantidade de ração em produção de carne, porém estatisticamente os resultados não se apresentam significativos $(\mathrm{P}>0.10)$.

É importante ressaltar que a maioria das diferenças numéricas dos parâmetros zootécnicos avaliados nas diferentes linhagens, são devidas a fatores ambientais e à forma de manejo, não se constatando qualquer diferença que possa comprovar o melhor ou o pior desempenho de determinada linhagem.

\section{REFERÊNCIAS BIBLIOGRÁFICAS}

ANDRIGUETTO, J.M.; FLEMMING, J.S., PERLY, L.; MINARDI, I. Normas e Padrões de Nutrição e Alimentação Animal. Ed. Nobel São Paulo. SP 146p. 1996.

ARBOR ACRES FARMS. Management Manual. Connecticut, 32p, 1996.

COBB BROILER. Broiler feeding and management Connecticut, 16p, 1992.

COBB VANTRESS. Guia de manejo para el parrrillero Cobb- 500. Arkansas, 1994.

GIANNONI, M.; GIANNONI, M.L. Genética e melhoramento do rebanho nos trópicos. São Paulo: Nobel, p.375, 1983.

HUBBARD FARMS. Standard and hy-yeld breeder management guide. New Hampshire, $16 \mathrm{p}, 1996$.

HUBBARD FARMS. Parent breeder management guide. New Hampshire, 18p, 1995.

HUBBARD FARMS. Manual de manejo para el pollo de engorde. New Hampshire, 12p, 1992.

ISA VEDETTE. Guia de Manejo. Institut de Selection Animal. Lyon. 1996.

PEREIRA, J.C.C.. Melhoramento genético aplicado aos animais domésticos. Belo Horizonte: Escola de Medicina Veterinária da UFMG, p.299-325, 1983.

PERFORMANCE OBJECTIVES. Parents and broiler Ross breeeders. Alabama, 6p, 1995.

ROSS BREEDERS. Manual broiler guide. Alabama, . 25p. 1995.

ROSS BROILER. Management guide. Alabama, 22p, 1996. 